\title{
Inactivation of the tumor suppressor gene von Hippel-Lindau (VHL) in granulocytes contributes to development of liver hemangiomas in a mouse model
}

Hannah L. Bader ${ }^{1 *}$ and Tien Hsu ${ }^{1,2^{*}}$ (D)

\begin{abstract}
Background: Mutations in the tumor suppressor gene von Hippel-Lindau (VHL) underlie a hereditary cancer syndrome-VHL disease-and are also frequently observed in sporadic renal cell carcinoma of the clear cell type (cCRCC). VHL disease is characterized by malignant and benign tumors in a few specific tissues, including ccRCC, hemangioblastoma and pheochromocytoma. The etiology of these tumors remains unresolved.

Methods: Conditional inactivation of the VHL gene in mouse (Vh/h) was generated to examine the pathophysiological role of the VHL gene function. Specific cell populations were isolated by fluorescence-activated cell sorting (FACS) and bone marrow transplants were performed to identify the Vhlh-inactivated cells responsible for the phenotype.

Results: Previously we showed that inactivation of Vh/h in a subpopulation of kidney distal tubule cells resulted in hyperplastic clear-cell lesions and severe inflammation and fibrosis. Here, we show that this knockout mouse strain also develops Hif-2a-dependent vascular overgrowth (hemangioma) and extramedullary erythropoiesis in the liver. However, $V h / h$ inactivation was not detected in the liver parenchyma. We instead demonstrate that in these mice, Vhlh is inactivated in liver granulocytes and that hemangiomas are partially rescued in knockout mice reconstituted with wild-type hematopoietic stem cells, indicating the involvement of bone-marrow-derived leukocyte. Interestingly, bone marrow from knockout mice failed to generate the liver phenotype in wild-type recipients, suggesting that an additional cell type that is not derived from the bone marrow is involved in the development of the hemangioma phenotype.
\end{abstract}

Conclusion: These results support the idea that the development of a full-blown VHL disease phenotype requires inactivation of the VHL gene not only in the tumor proper, but also in the stromal compartment.

Keywords: von Hippel-Lindau, Hypoxia-inducible factor 2 alpha, Hemangioma, Placental growth factor, Extramedullary erythropoiesis, Hemangioblastoma, Neutrophil, Angiogenesis

\section{Background}

Patients with VHL disease are heterozygous for $V H L$ mutations, and develop tumors when the function of the remaining wild-type $V H L$ allele is lost via somatic mutation or epigenetic silencing [1]. VHL tumors, which can occur in several different tissues, are characterized by hypervascularity and a clear cell appearance in histological

\footnotetext{
* Correspondence: baderh@bu.edu; tienhsu@ncu.edu.tw

${ }^{1}$ Department of Medicine, Boston University School of Medicine, Boston, MA, USA

Full list of author information is available at the end of the article
}

preparations. VHL mutations are also frequently observed in sporadic renal cell carcinoma (ccRCC). In addition, specific $V H L$ missense mutations have been described that do not cause tumors, but result instead in recessive polycythemia, a disease characterized by an overproduction of erythrocytes [2-4].

VHL protein (pVHL) is an essential negative regulator of the hypoxia-inducible factor (HIF), a transcription factor induced by low oxygen tension [5]. HIF induces a metabolic switch from oxidative phosphorylation to glycolysis, which is essential for cell survival under hypoxic 
conditions. HIF also promotes angiogenesis and erythropoiesis through induction of cytokines such as vascular endothelial growth factor (VEGF) and erythropoietin (EPO). The active HIF transcription factor is a dimer consisting of an $\alpha$ and a $\beta$ subunit $[1,5]$. The $\beta$ unit-known as HIF- $1 \beta$ or ARNT (arylcarbon receptor nuclear translocator)-is ubiquitously and constitutively expressed. In contrast, the HIF- $\alpha$ subunits (HIF- $1 \alpha$, HIF- $2 \alpha$ and HIF- $3 \alpha$ ) are regulated by oxygen tension. Under normoxic conditions, HIF- $\alpha$ is hydroxylated. The hydroxylated form is recognized by an ubiquitin ligase and undergoes ubiquitination, followed by proteasome-mediated degradation. Hydroxylation is oxygen dependent, and is inhibited under hypoxic conditions. Thus, hypoxia leads to stabilization of the HIF- $\alpha$ protein, allowing formation of the dimeric HIF transcription factor and transactivation (or repression) of HIF responsive genes.

$\mathrm{pVHL}$ is the substrate recognition component of the multimeric ubiquitin-ligase complex that mediates HIF- $\alpha$ ubiquitination [1, 5]. VHL gene inactivation therefore leads to normoxic stabilization of HIF- $\alpha$ and inappropriate activation of the HIF transcription factor. The formation of VHL tumors is thought to be driven in large part by genes induced or suppressed by HIF [5]. However, loss of $H I F$-independent functions of $V H L$, and mutations of additional tumor suppressor genes, likely also contribute to tumorigenesis $[1,6,7]$. Recent animal model and cancer genome studies have indicated that $V H L$ mutations are necessary but insufficient for tumorigenesis $[6,8-10]$. Such second and even third hits conceivably can be additional genetic or epigenetic changes within the same cells, or can be within a separate cell population that contributes to the formation of tumor microenvironment. The requirement for additional tumor suppressor gene(s) in ccRCC formation was supported by the construction of Vhlh (mouse allele of $V H L$ )-Bap1 double knockout [11]. $B A P 1$ gene mutations have been observed in $\sim 10 \%$ of ccRCC samples [9, 10]. Vhlh-Bap1 double knockout generated clear-cell lesions that resemble carcinoma [11]. On the other hand, mutations in the cancer stromal cells, including those of the well-known tumor suppressor genes p53 and PTEN, have been documented that contribute to cancer progression \{reviewed in [12]\}. It is therefore possible that in VHL patients, $V H L$ inactivation could also occur in the tumor microenvironment (stroma) in addition to the tumor itself.

One of the most frequently observed tumors in VHL patients besides ccRCC is hemangioblastoma, a highly vascularized tumor with extramedullary hematopoiesis that occurs in the central nervous system and the retina [13]. Hemangioblastomas cause considerable morbidity and mortality despite being benign. Hemangioblastomas are sometimes referred to as vascular tumors; however, biallelic inactivation of $V H L$ was detected in the stromal compartment of the vascular tumors [14-16], which also have a clear cell appearance. Vascular overgrowth is therefore likely induced by pro-angiogenic cytokines released by these "stromal cells." In addition, hemangioblastomas frequently contain foci of extramedullary erythropoiesis and the $\mathrm{VHL}^{-}$stromal cells exhibit multipotency that may be of embryonic origin [17-19]. There are no mouse models that recapitulate hemangioblastoma. However, several VHL mouse models develop hemangiomas-an overgrowth of irregularly shaped and leaky blood vessels-in the liver [20-23]. Hemangiomas have been observed in the liver of germline $\mathrm{Vhlh}^{+/-}$mice [20] and in mosaic Vhlh biallelic deletion mice induced by conditional $\beta$-actindriven Cre [21]. These two models contain heterozygous and homozygous, respectively, Vhlh mutants in most cell types, including hepatocytes and endothelial cells. More interestingly, liver hemangiomas were also observed in PEPCK-Cre driven Vhlh knockout, which inactivates Vhlh in renal proximal tubule cells and in 20 to $30 \%$ of hepatocytes [20, 22]. Likely due to early mortality, full-blown hemangiomas were not observed when a more hepatocytespecific Cre driver, Albumin-Cre, was used to inactivate Vhlh; nonetheless, numerous blood-filled vascular cavities, and foci of increased vascularization within the hepatic parenchyma were observed [20, 22]. Inactivation of Vhlh in hepatocytes with PEPCK-Cre or Albumin-Cre also led to erythrocytosis-overproduction of erythrocytes-due to increased expression of Epo [20,22], although hemangiomaassociated extramedullary erythropoiesis-as observed in hemangioblastoma-was not observed. Hif- $2 \alpha$ was found to mediate up-regulation of erythropoietin and multiple pro-angiogenic cytokines in these mouse models, and in-

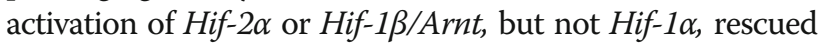
hemangiomas in PEPCK-Cre or Albumin-Cre driven Vhlh knockout mice [22, 24].

Previously we showed that inactivation of Vhlh in a subpopulation of kidney distal tubules, using the HOXB7-Cre driver, resulted in Hif-1 $\alpha$-dependent hyperplastic clear-cell lesions and severe inflammation and fibrosis [25]. Here, we report that the same $H O X B 7-C r e$ driven Vhlh conditional knockout mice also developed liver hemangiomas as well as extramedullary erythropoiesis. Interestingly, in contrast to the previous mouse models, we did not detect Vhlh inactivation in hepatocytes. Instead, Vhlh inactivation was detected in liver granulocytes in the knockout mice. In support of a myeloid component in the development of hemangiomas in the liver, reconstitution of the knockout mice with wild-type hematopoietic stem cells partially rescued the hemangioma phenotype. Further analysis showed that the granulocyte population contained the Vhlh deleted allele. In addition, granulocytes (neutrophils) in livers of the HOXB7-Cre driven Vhlh knockout mice were found to over-express placental growth factor (PIGF) that has been shown to promote angiogenesis. Thus, this mouse model supports the notion that a bone 
marrow-derived stromal component with $V H L$ loss-offunction contributes to the development of the full extent of the VHL disease phenotype.

\section{Methods}

\section{Animal protocol and mouse strains}

All of the procedures were conducted in accordance with the US Public Health Service Policy on Humane Care and Use of Laboratory Animals. Mice used in these studies were maintained in Boston University Medical Center facility according to protocols approved by the Institutional Animal Care and Use Committee. Mouse strains used were in C57BL/6 background and have been described previously [25]. For generation of bone marrow chimeras, B6.SJL-Ptprc ${ }^{a}$ Pepc /BoyJ ("B6 CD45.1") as well as RosaLacZ was purchased from Jackson Laboratories (Bar Harbor, Maine, USA).

\section{Reagents}

Phosphate-buffered saline (PBS), Dulbecco's phosphatebuffered saline (DPBS), Dulbecco's modified eagle medium (DMEM) and HEPES were obtained from Gibco/Life Technologies (Carlsbad, CA, USA). Fetal bovine serum (FBS) was obtained from Hyclone (Logan, UT, USA). Sterile 0.5 M EDTA stock solution, pH7.5, was obtained from Boston Bioproducts (Ashland, MA, USA). Fluorescenceactivated cell sorting (FACS) buffer was prepared as follows: $0.5 \% \mathrm{FBS} / 2 \mathrm{mM}$ EDTA in DPBS. Red blood cell lysis buffer, Fc-block and antibodies for flow cytometry (except anti-CD45 antibody) were obtained from eBioscience (San Diego, CA, USA). Cell strainers $(40 \mu \mathrm{m}$ or $70 \mu \mathrm{m})$ were obtained from ThermoFisher Scientific (Waltham, MA, USA).

\section{Histology and immunohistochemistry}

Livers were fixed overnight in $10 \%$ neutral buffered formalin and were embedded in paraffin. $4 \mu \mathrm{m}$ thick paraffin sections were stained with hematoxylin and eosin (H\&E) according to standard procedures. For immunohistochemistry, $4 \mu \mathrm{m}$ thick paraffin sections were dewaxed, and heat mediated antigen retrieval was performed with citrate buffer, $\mathrm{pH} \mathrm{6}$, for $40 \mathrm{~min}$. Endogenous peroxidase was quenched by incubating sections for $15 \mathrm{~min}$ in methanol with $0.3 \% \mathrm{H}_{2} \mathrm{O}_{2}$ or peroxidase block (Peroxidased 1, Biocare Medical, Concord, CA). Endogenous biotin was blocked with avidin-biotin blocking kit (Vector Laboratories, Burlingame, CA, USA), followed by 30 min blocking with $3 \%$ or $10 \%$ (GFP stain) normal goat serum (SigmaAldrich, St. Louis, MO) in PBS. Staining and washing was performed with PBS, $0.05 \%$ Tween 20 (Sigma-Aldrich). Sections were incubated overnight at $4{ }^{\circ} \mathrm{C}$ with primary antibody (1:50 rat anti-CD45, clone 30-F11, Molecular Probes/Life Technologies, Carlsbad, CA, USA; 1:100 rabbit anti-mouse Plgf, Origene/Acris Antibodies, Rockville, MD,
USA; 1/500 chicken anti-GFP, Abcam) and incubated for $45 \mathrm{~min}$ with appropriate biotinylated secondary antibody (Vector Laboratories) at 1/500 (rabbit and chick secondary) or $1 / 1000$ (rat secondary). After washing $3 \times 5 \mathrm{~min}(\mathrm{CD} 45)$ or $4 \times 15$ min [placental growth factor Plgf), GFP], sections were incubated for $45 \mathrm{~min}$ with streptavidin-conjugated horseradish peroxidase (Invitrogen/Zymed, Carlsbad, CA, USA) at 1/1000 (CD45 stain) or with ABC Elite Kit (Vector Laboratories; Plgf, GFP stain). Sections were washed again for $3 \times 5 \mathrm{~min}$ (CD45) or $4 \times 15 \mathrm{~min}$ (Plgf, GFP) and were incubated for 5-10 min with peroxidase substrate (DAB, Vector Laboratories). Sections were counterstained with hematoxyline and mounted with permount (ThermoFisher Scientific).

\section{Preparation of single cell suspensions from liver}

Livers were dissected out taking care to minimize bleeding, and were rinsed with DPBS to wash off excess blood. For wild-type samples, small pieces of liver were dissected out from the left and median lobe (lobe encasing the gallbladder). For knockout samples, liver pieces containing hemangiomas were dissected out. In some cases hemangioma tissue was pooled from two mice to obtain enough material. Next, liver tissue was minced and resuspended in 5-10 ml digestion buffer consisting of ice-cold DMEM with $5 \mathrm{mg} / \mathrm{ml}$ (or $800 \mathrm{U} / \mathrm{ml}$ ) collagenase (trypsin-free Collagenase, CLS-4, Worthington Biochemical Corporation, Lakewood, NY, USA) and $20 \mathrm{mM}$ HEPES. Digestion was performed at $4{ }^{\circ} \mathrm{C}$ for $1-1.5 \mathrm{~h}$ in 5 -ml round bottom polypropylene tubes with overhead rotation. The digest was then diluted 2-fold in FACS buffer, EDTA was added to a final concentration of $2 \mathrm{mM}$, and the cell solution was strained through a $70-\mu \mathrm{m}$ strainer. Next, cells were pelleted at $250 \mathrm{xg}$ for $8 \mathrm{~min}$ at $4{ }^{\circ} \mathrm{C}$, and resuspended in ice-cold red blood cell lysis buffer (from eBioscience, San Diego, CA, USA). Red blood cell lysis was performed for $3 \mathrm{~min}$ on ice. After washing, liver cells were resuspended in FACS buffer and stained as described below.

\section{Flow cytometry and FACS}

Staining was carried out in $1.5-\mathrm{ml}$ tubes. For wash steps, cells were pelleted in a tabletop centrifuge $\left(250 \mathrm{xg}\right.$ at $4{ }^{\circ} \mathrm{C}$ for $5 \mathrm{~min}$ ). After treatment with red blood cell lysis buffer (see preparation of single cell suspensions), cells were resuspended in ice-cold FACS buffer and concentration was adjusted to $1 \times 10^{6}$ cells $-5 \times 10^{6}$ cells per $100 \mu \mathrm{l}$. Cells were incubated with Fc-block (1:100) for 5 min on ice, before adding primary antibodies. After cells were incubated for $20 \mathrm{~min}$ on ice with primary antibodies, live/dead stain was performed. For propidium iodide staining, cells were washed once with $1 \mathrm{ml}$ FACS buffer, and resuspended in FACS buffer with $1 \mu \mathrm{g} / \mathrm{ml}$ propidium iodide $(1 \mathrm{mg} / \mathrm{ml}$ stock solution obtained from Life Technologies). Cells were then 
transferred to round bottom polypropylene tubes for sorting/analysis (no washing required after propidium iodide step). For staining with Aqua Blue Live/Dead solution (Life Technologies), cells were resuspended in $1 \mathrm{ml}$ FACS buffer with 1:1000 of Aqua Blue stock solution (Life Technologies; stock solution prepared according to instructions of manufacturer) and were incubated for $15 \mathrm{~min}$ at $4{ }^{\circ} \mathrm{C}$ with overhead rotation (washing after antibody staining and live/ dead staining in one step). Subsequently, cells were washed once with $1 \mathrm{ml}$ FACS buffer, and were resuspended in FACS buffer and transferred to round bottom polypropylene tubes for sorting/analysis; cell suspensions were filtered through a $40-\mu \mathrm{m}$ strainer. For sorting of CD45+ cells, cells were stained with CD45-APC (1:200; Molecular Probes/Life Technologies), followed by propidium iodide stain (Life Technologies). For quantification and sorting of erythrocyte progenitors, cells were triple stained with the following antibodies: CD45-Percp-Cy5 1:200, TER119-APC 1:100 and CD71-PE 1:200; followed by Aqua Blue Live/Dead stain (Life Technologies). For determination of chimerism in peripheral blood, cells were double-stained with CD45.1-PE and CD45.2-APC at 1:100 and dead cells were gated out according to size (FSC vs SSC plots). Cell sorting and analysis of liver samples was performed with the FACS Aria II SORP (Becton-Dickinson) or Beckman-Coulter Moflo.

\section{Liver colony forming unit assay}

Livers were dissected out taking care to minimize bleeding, and were rinsed with $20 \mathrm{ml}$ DPBS to rinse off excess blood. Subsequently, homogenization was performed as described above but without collagenase treatment. After passing the cell suspension through a $70-\mu \mathrm{m}$ strainer, cells were pelleted (250 xg at $4{ }^{\circ} \mathrm{C}$ for $8 \mathrm{~min}$ ) and resuspended in $20 \mathrm{ml}$ DPBS containing $2 \%$ FBS. For cell counting, a small aliquot was stained with an acridine orange and propidium iodide solution (AO/PI solution, Nexcelcom, Lawrence, MA, USA) according to the instructions of the manufacturer, and counted with the cellometer (Nexcelcom). $4.8 \times 10^{5}$ live cells in $300 \mu \mathrm{l}$ DPBS were then added to $3 \mathrm{ml}$ of MethoCult GF M3434 (Stem Cell Technologies, Vancouver, BC, Canada) and plated out into two 3-cm tissue culture dishes, following instructions of the manufacturer. BFU-E colonies per plate were quantified in a blinded fashion after 7-8 days, and were averaged for each sample ( 2 plates per sample).

\section{$\beta$-galactosidase staining of organs}

Chemicals for staining were obtained from ThermoFisher Scientific. Livers and kidneys were fixed in $4 \%$ paraformaldehyde in PBS for $\sim 4 \mathrm{~h}$ at room temperature. Organs were then washed $(3 \times 30 \mathrm{~min})$ with wash buffer (0.1 $\mathrm{M} \mathrm{NaH}_{2} \mathrm{PO}_{4}, 0.1 \mathrm{M} \mathrm{Na}_{2} \mathrm{HPO}_{4}, 2 \mathrm{mM} \mathrm{MgCl}, 0.01 \%$ deoxycholate, $0.02 \% \mathrm{NP}-40$ ) and stained overnight at $4{ }^{\circ} \mathrm{C}$ with staining buffer (wash buffer with $5 \mathrm{mM}$ ferrocyanide,
$5 \mathrm{mM}$ ferricyanide and $1 \mathrm{mg} / \mathrm{ml}$ 5-bromo-4-chloro-3-indolyl- $\beta$-D-galactopyranoside (X-Gal). Organs were photographed, post-fixed for 15 min with $4 \%$ paraformaldehyde in PBS, and were embedded in paraffin. $4 \mu \mathrm{m}$ thick paraffin sections were prepared and counter-stained with $\mathrm{Nu}$ clear Fast Red (Vector Laboratories) and analyzed for $\beta$-galactosidase staining.

\section{Isolation of genomic DNA and polymerase chain reaction (PCR) for detecting Vhlh deletion}

DNA from liver tissue was obtained using the DNAeasy blood and tissue kit (Qiagen, Valencia, CA, USA) according to instructions of the manufacturer. Sorted cells (10,000-500,000) were pelleted in a table top centrifuge (300 xg, $5 \mathrm{~min}$ ), frozen in $<100 \mu \mathrm{l}$ DPBS with $2 \% \mathrm{FBS}$, and stored at $-80{ }^{\circ} \mathrm{C}$. Subsequently, DNA was obtained with the Qiamp Micro DNA kit (Qiagen) following the protocol for DNA isolation from small amounts of blood. Vhlh primers for detection of the Vhlh flox allele and wild-type allele have been described before [22]; sequences are as follows: Vhlh-wt/flox forward primer (FW1), ctaggcaccgagcttagaggtttgcg; Vhlh-wt/flox reverse primer (Rev1), ctgacttccactgatgcttgtcacag. PCR products are $\sim 290 \mathrm{bp}$ ( $w t$ allele) and 460 bp (floxed allele). The site of the forward primer is lost upon recombination; the Vhlh-wt/flox primers therefore cannot amplify the recombined/deleted Vhlh allele. Generic primers were used to detect Cre: $F W$, atccgaaaagaaaacgttga; Rev, atccaggttacggatatagt; Cre-PCR product is $\sim 700 \mathrm{bp}$. Vhlh deletion primers were designed as follows: the forward primer (FW2) is situated downstream of the second HindIII restriction site, and upstream of the NdeI restriction site within the $5^{\prime}$ untranslated sequence of the murine Vhlh gene. The reverse primer (Rev2) is situated downstream of the HindIII restriction site within the first intron of the murine Vhlh gene [20]. The sequences are as follows: Vhlh-del forward primer (FW2): ggaaccatctcttctctgatagagc; Vhlh-del reverse primer (Rev2): gctggttgcttcagacacaatcttg. The Vhlh del primers flank exon 1 (see Fig. 4c). In the presence of exon 1, the sequence is very long $(\sim 4 \mathrm{~kb})$ and is therefore not amplified under stringent PCR conditions (e.g., short extension time). In the presence of Cre, exon 1 is excised, resulting in a much shorter sequence, allowing amplification of the recombined/deleted Vhlh allele. The Vhlh-del PCR product is $\sim 800 \mathrm{bp}$. Identity of the product was confirmed by sequencing.

\section{Serum collection and ELISA for erythropoietin}

Peripheral blood was collected in heparinized microcapillaries (ThermoFisher Scientific), and was transferred into collection tubes with clotting activator (BD Microtainer SST, Becton Dickinson, Waltham, MA, USA). Blood was incubated for $\sim 5-10 \mathrm{~min}$ at room temperature, 
and centrifuged at full speed in a table-top centrifuge. The serum (corresponding to supernatant) was collected and stored at $-80{ }^{\circ} \mathrm{C}$ for up to 4 months. Subsequently, erythropoietin ELISA was performed with Quantikine erythropoietin ELISA kit (RD systems Inc, Minneapolis, MN, USA) according to instructions of the manufacturer.

\section{Preparation of CDNA and quantitative PCR}

Liver RNA was isolated using Trizol in combination with Purelink RNA Mini kit (Invitrogen/Life Technologies) according to instructions of manufacturer. DNA was digested with on-column DNAse I digestion kit (Invitrogen/Life Technologies) according to instructions of manufacturer. Sorted cells $(\sim 20,000)$ were pelleted, resuspended in Quiazol (Qiagen) and stored at $-80{ }^{\circ} \mathrm{C}$. Subsequently, RNA was purified using the miRNAeasy Kit (Qiagen) according to instructions of the manufacturer. After elution, RNA from sorted cells was dried in GenTegra ${ }^{\mathrm{TM}}-\mathrm{RNA}$ tubes (GenTegra, Pleasanton, CA, USA) and was resuspended in $\sim 5 \mu$ l of water. Liver RNA $(1 \mu \mathrm{g})$ or entire RNA obtained from $\sim 20,000$ sorted cells was reverse transcribed with AMV First Strand cDNA kit (liver) or Protoscript II first strand synthesis kit (sorted cells; both kits from New England Biolabs, Ipswich, MA, USA) according to instructions of the manufacturer. Real-time PCR was performed with Power SYBR Green Mastermix (Applied Biosystems/Life Technologies) using a StepOne Real time PCR system (Applied Biosystems/Life Technologies). The following primers from the Universal Probe Library (Roche/Life Technologies) were used: $18 \mathrm{~s}$ forward primer, gcaattattcccatgaacg; $18 \mathrm{~s}$ reverse primer, gggacttaatcaacg caagc; erythropoietin forward primer, ccctgctgcttttactctcc; erythropoietin reverse primer, gggggagcacagaggact; prolylhydroxylase 3 (Phd3) forward primer, tgtctggtacttcgatgctga; reverse primer, agcaagagcagattcagtttttc.

\section{Hoechst staining and bone marrow transplant}

Staining with Hoechst 33342 (Life Technologies) was performed as described previously [26, 27], with the following modification: to increase the yield, Hoechst was titrated so that cells were understained (to achieve a Hoechst negative side population of $\sim 1 \%)$. Subsequently, only the least Hoechst positive cells (comprising 0.2-0.5\% of all cells) were sorted, and 1000 SP were used per recipient; $3 \times 10^{5}$ unfractionated bone marrow cells were cotransplanted to improve survival. Recipients were lethally irradiated one day before transplantation with a split dose of 14 gray ( 2 month old recipients) or 11 gray (4 week old recipients) separated by $2 \mathrm{~h}$. For 2 weeks after the transplant, starting with the day of the transplant, recipients received antibiotics in the drinking water. To examine chimerism using flow cytometry, peripheral blood was collected in heparinized microcapillaries (ThermoFisher Scientific). Blood samples $(\sim 100 \mu \mathrm{l})$ were then transferred to $1.5 \mathrm{ml}$ tubes containing $100 \mu \mathrm{l}$ DPBS with $2 \mathrm{mM}$ EDTA. $1 \mathrm{ml}$ of red blood cell lysis buffer was added to samples, and red blood cell lysis was carried out $5 \mathrm{~min}$ at room temperature. After adding $10 \mathrm{ml}$ of ice cold FACSbuffer, samples were transferred to $15 \mathrm{ml}$ centrifuge tubes and were centrifuged ( $8 \mathrm{~min}, 250 \mathrm{~g}, 4{ }^{\circ} \mathrm{C}$ ). Cells were then resuspended in $100 \mu \mathrm{l}$ FACS-buffer, and stained with antibodies for flow cytometry (see above).

\section{Statistical analysis}

Unpaired, two-tailed $t$-tests were performed; where necessary, Welch's correction for unequal variances was applied. All analyses were performed using GraphPad Prism Software (La Jolla, CA, USA). For group comparisons, $p$-values were calculated with GraphPad prism software, and false discovery rate (FDR) was calculated manually using Bonferroni post-test or Benjamini and Hochberg FDR formula.

\section{Results}

Hepatic hemangioma phenotype in the HOXB7-Cre driven Vhlh knockout mice

HOXB7-Cre is widely used to target the collecting ducts of the kidney $[28,29]$. However, we recently found that this Cre driver is also expressed in a subset of distal tubules in the kidney cortex. Conditional inactivation of Vhlh using this Cre driver resulted in fully penetrant hyperplasia, cysts, clear-cell lesions, inflammation and fibrosis in the kidney, with the hyperplastic lesions arising primarily from Tamm-Horsfall positive distal tubules [25].

Interestingly, these HOXB7-Cre; $\mathrm{Vhlh}^{f l / f l}$ mice also developed hemangiomas in the liver starting at 3 weeks of age. The diseased liver showed an overgrowth of irregularly shaped, abnormally large and leaky blood vessels (compare Fig. 1a, b). Erythrocytes (Fig. 1b) and leukocytes (Fig. 1c) accumulated within the hemangiomas, based on pathologist's assessment. Leukocytes were also identified adjacent to hemangiomas by immunohistochemistry for CD45-expressing cells (Fig. 1d; based on pathologist's assessment). Older mice ( $>3$ months) additionally developed fibrotic lesions (Fig. 1e, f), indicating involvement of an immune component. The development of hemangioma starts between 3 and 4 weeks of age and the penetrance reached $90 \%$ at 6 weeks (Fig. 1g). In contrast, the development of kidney lesions in this knockout mouse strain begins at 8 weeks and becomes fully penetrant at 12 weeks [25].

\section{Extramedullary erythropoiesis in the liver of $\mathrm{HOXB7-Cre}$ driven Vhlh knockout mice}

Hemangioblastoma associated with the VHL disease often presents with extramedullary erythropoiesis [17]. Indeed in our model, quantification of erythrocyte progenitors in livers of wild-type and knockout mice by flow cytometry 

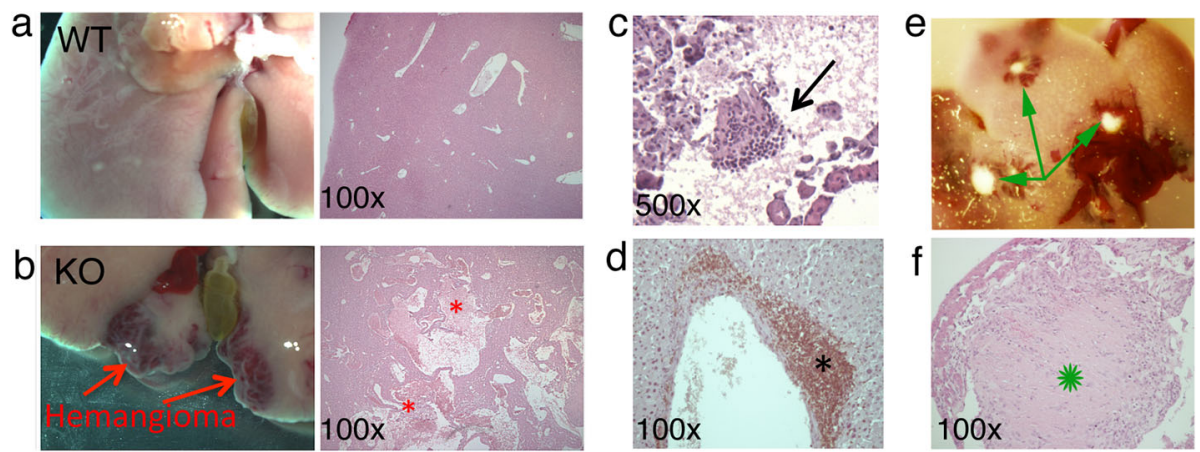

g
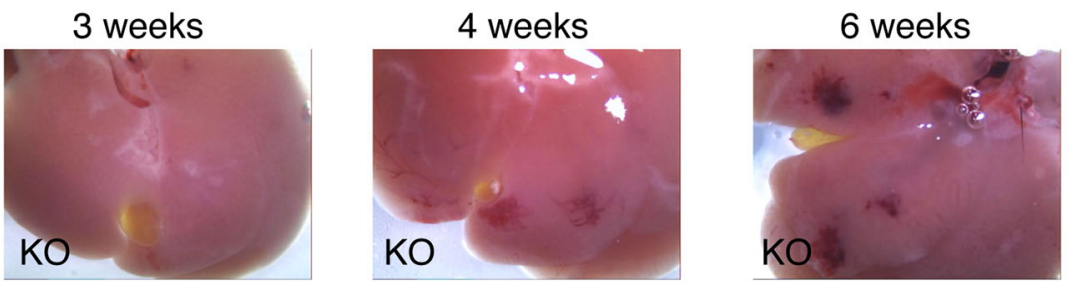

\begin{tabular}{l|c|c|c} 
& 3 weeks & 4 weeks & 6 weeks \\
\hline $\begin{array}{l}\text { penetrance of } \\
\text { liver hemangiomas }\end{array}$ & $20 \%(1 / 5)$ & $75 \%(3 / 4)$ & $90 \%(9 / 10)$
\end{tabular}

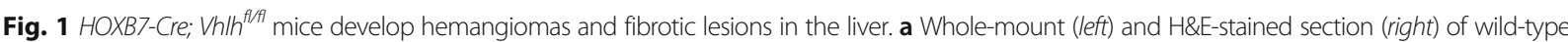
mouse liver from a HOXB7-Cre; Vh/h ${ }^{+/+}$mouse. b Whole-mount (left) and H\&E-stained section (right) of knockout mouse liver from a HOXB7-Cre; Vhlh ${ }^{f / / t}$ mouse. Hemangiomas are indicated by arrows and erythrocyte-filled blood vessels are indicated by asterisks (*; interpreted by a pathologist). $\mathbf{c}$ H\&E-stained liver section from a HOXB7-Cre; Vh/h fl/fl mouse. A cluster of leukocytes within the hemangioma is indicated by an arrow (interpreted by a pathologist). $\mathbf{d}$ Liver section from a HOXB7-Cre; Vh/h ${ }^{\text {fl/fl }}$ knockout mouse, stained for CD45 (a pan-leukocyte marker). A cluster of leukocytes near the blood vessel is indicated (*; interpreted by a pathologist). e Whole-mount of liver from a HOXB7-Cre; Vh/h ${ }^{\text {fl/fl }}$ knockout mouse. Fibrotic foci are indicated by arrows. $\mathbf{f}$ H\&E-stained section of liver from a HOXB7-Cre; Vh/h ${ }^{f / f l}$ knockout mouse. A large fibrotic site is indicated (*; interpreted by a pathologist). $\mathbf{g}$ Representative images of whole-mounted livers of 3, 4 and 6-week old HOXB7-Cre; Vh/h/flf mice. The penetrance of hemangiomas at 3, 4 , and 6 weeks of age is indicated in the table below the images. Numbers in brackets refer to mice with hemangiomas versus total mice analyzed ( $\mathrm{n}$ with hemangiomas/n total)

(TER119 + CD71+; pooled data from $>2$ month old mice; Fig. 2a) indicated that there was a $>10$-fold increase in erythrocyte progenitors in livers of knockout mice. The extent of increase in TER119 + CD71+ cell number is in agreement with colony forming unit assay that functionally defines erythrocyte progenitors (Fig. 2b). Epo is a key cytokine that promotes erythropoiesis, including the formation of BFU-E and the subsequent differentiation steps to form erythrocytes [30]. Its expression is induced under hypoxic conditions by HIF transcription factor and in VHL mutant cells. We indeed demonstrated that the increased number of erythrocyte progenitors correlated with over-expression of Epo: Epo mRNA was upregulated in liver of the knockout mice (Fig. 3a), and Epo protein was increased in the serum (Fig. 3b) in the Vhlh knockout mice. However, Vhlh deletion is not present in these progenitor cells (Fig. 3c), indicating that a non-erythroid $\mathrm{Vhlh}^{-}$component is responsible for inducing extramedullary erythropoiesis.
Hepatic phenotypes of HOXB7-Cre driven Vhlh knockout mice are Hif-2a-dependent

Previous conditional knockout mice with Vhlh inactivation in hepatocytes developed liver hemangiomas and erythrocytosis, but no hemangioma-associated extramedullary erythropoiesis [22, 24]. In those mouse models, hemangiomas and erythrocytosis were rescued by $H$ if $-2 \alpha$ inactivation. We therefore examined the effects of Hif- $2 \alpha$ inactivation on the phenotypes observed in our mouse model by generating HOXB7-Cre; $V h l h^{f l / f l}$; Hif- $2 \alpha^{f l / f l}$ double knockouts. Hif- $2 \alpha$ knockout rescued elevated serum Epo (Fig. 3b) as well as extramedullary erythropoiesis, as assessed with colony forming unit assay (Fig. 2b). Hif- $2 \alpha$ inactivation also ameliorated the hemangioma phenotype. The onset of hemangiomas was delayed ( $25 \%$ vs $90 \%$ at 6 weeks), and the number of hemangiomas per liver was significantly reduced in 2 to 3 -month old double knockouts (Fig. 3d). 


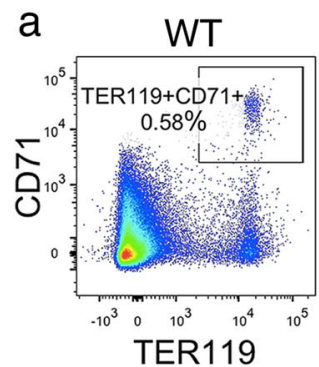

b
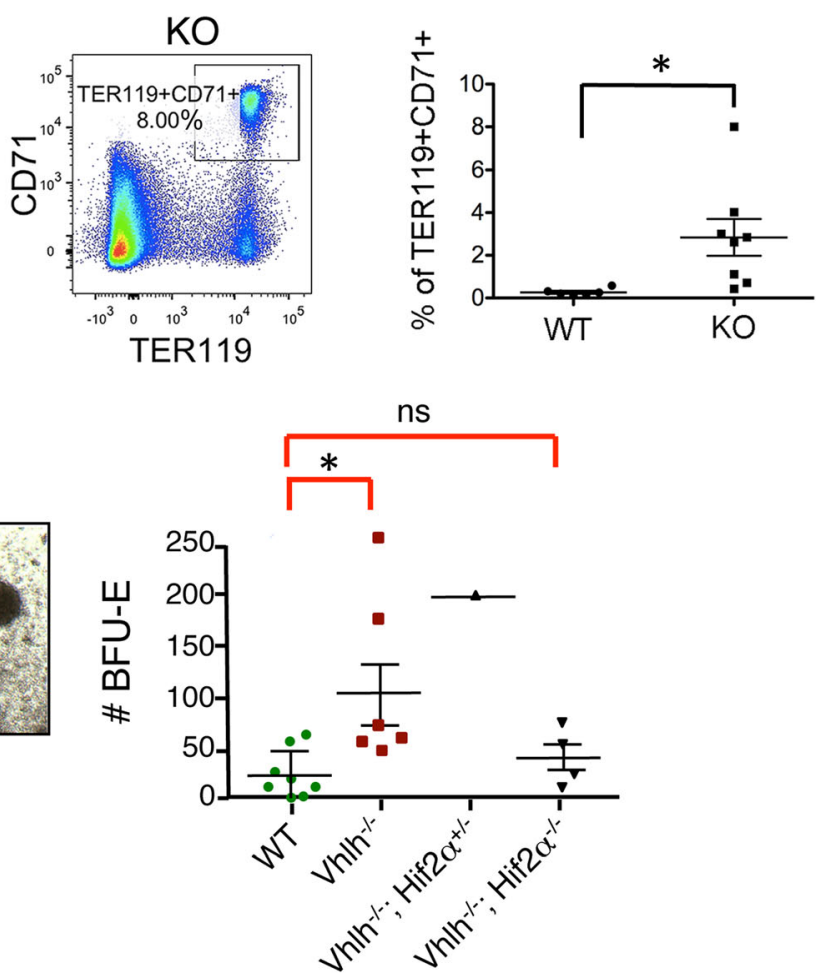

Fig. 2 Extramedullary erythropoiesis in Vh/h knockout mice. a Erythrocyte progenitors are increased by $\sim 10$-fold in livers of HOXB7-Cre; Vh/h ${ }^{\text {flfl }}$ knockout mice. Liver cell suspensions were prepared by mincing livers, followed by collagenase digestion and treatment with red blood cell lysis buffer (see Methods). Flow cytometric quantification of erythrocyte progenitors (TER119+CD71+) was performed. Shown are representative FACS-plots (left pane/s) and quantification (right panel). Gate was set on live CD45+ cells, and doublets were gated out. b Quantification of erythroid progenitors with

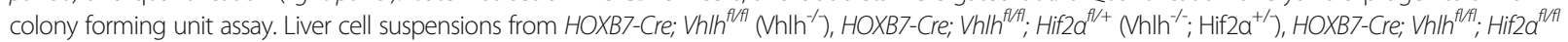

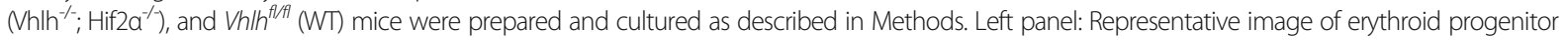
colonies (BFU-E) from a Vhlh knockout mouse. Right panel: Quantification of BFU-Es. While Vh/h knockout increased the number of BFU-E compared to that obtained from liver cell suspensions of Cre negative mice (WT), no difference was seen in the number of BFU-Es from WT and HOXB7-Cre VhIh-Hif-2a double

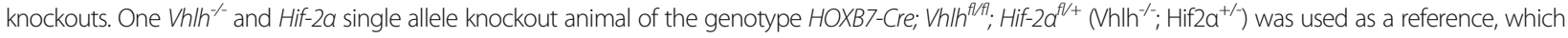
showed increased BFU-E number as in the Vh/h knockout. Mice were $>3$ months old. p-values were calculated using Student's t-test with Welch's correction. *: statistically significant $(p<0.05)$; ns: not significant

\section{Vhlh inactivation occurs in liver leukocytes, not in liver parenchyma}

Although the hemangioma phenotype recalled the outcome of previous hepatocyte-specific Vhlh knockout mice [20, 22], to our knowledge, the HOXB7-Cre driver used in our study has not been shown to function in the liver. We therefore used the ROSA-LacZ reporter [31] to determine whether this Cre driver mediated gene inactivation in the hepatocytes. As previously shown, Cre activity was readily detected in cortex and medulla of kidneys from HOXB7-Cre; Rosa-LacZ+ mice, whereas no Cre activity was detected in kidneys of Cre-negative ROSA-LacZ+ mice (Fig. 4a, left panel, compare Cre- and Cre + kidney) $[25,28,29]$. In contrast, we observed no overt Cre activity in the liver of HOXB7-Cre; ROSA$L a c Z+$ mice (Fig. 4b). We also did not observe steatosis in hepatocytes, a phenotype characteristic of Vhlh null hepatocytes [20, 22] (data not shown). It should be noted that the ROSA-LacZ locus is on the same chromosome as the Vhlh locus; therefore the reporter could not be used to trace Vhlh knockout cells. When an alternative and more sensitive PCR method was used, Vhlh inactivation was detectable in the livers of knockout mice. We used previously published primers to detect the wild-type and floxed Vhlh alleles [22], and designed new primers to detect the recombined (deleted) Vhlh allele (see Methods and Fig. 4c). Using these primers, we were able to detect the recombined Vhlh allele $\left(V h l h^{d e l}\right)$ in the livers of HOXB7-Cre; $\mathrm{Vhlh}^{f l / f l}$ mice (Fig. 4d, lanes labeled with $\mathrm{KO})$. Confirming the specificity of the primers, no deletion was detected in the livers of Cre-negative $\mathrm{Vhlh}^{f l f l}$ littermates (Fig. 4d, lanes labeled with WT). We also confirmed the identity of the Vhlh ${ }^{\text {del }}$ band by sequencing (data not shown). Next, both hemangiomas and gross-morphologically healthy looking liver tissue were dissected out of livers of HOXB7-Cre; Vhlh ${ }^{f l / f l}$ mice. Interestingly, a much stronger signal for the deleted allele was observed in hemangioma tissue compared to 


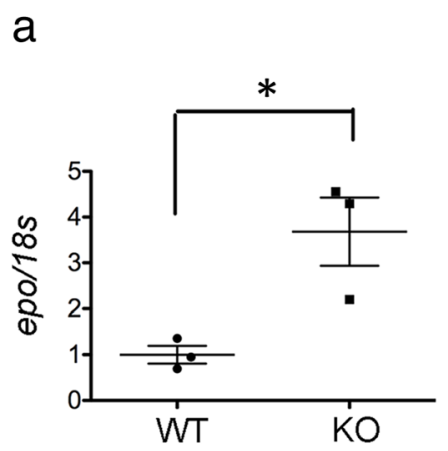

C

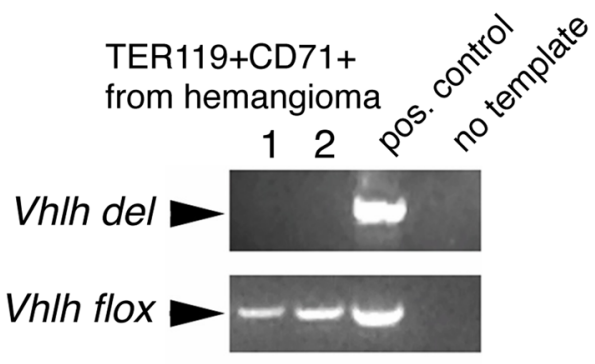

b

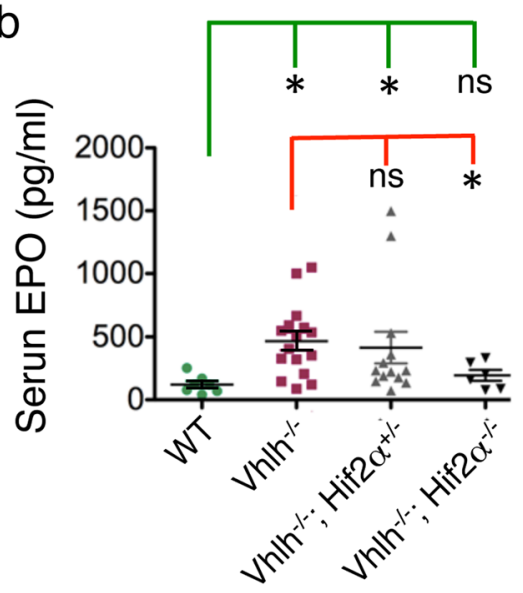

d

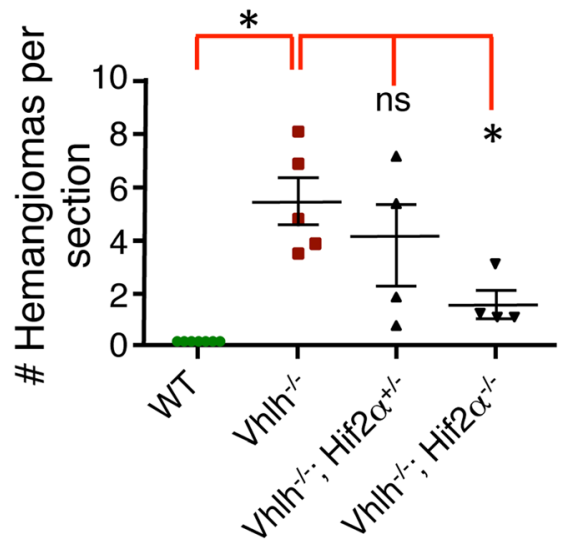

Fig. 3 Inactivation of Hif-2a rescues extramedullary erythropoiesis and suppresses hemangiomas. a Erythropoietin is over-expressed in livers of HOXB7-Cre; Vh/h ${ }^{f / A l}$ knockout mice: analysis of Erythropoietin (Epo) mRNA expression by quantitative PCR. $\mathbf{b}$ Serum erythropoietin levels were determined by ELISA for indicated genotypes. Data were pooled from mice of $>2$ months of age. Erythropoietin was elevated by $\sim 5$ folds in the serum of HOXB7-

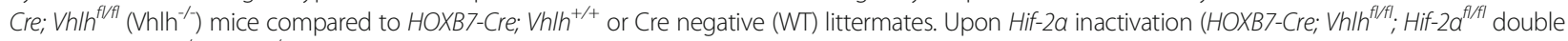
knockout) (Vhlh ${ }^{-1-} ; \mathrm{Hif}_{2} \mathrm{a}^{-1}$ ) serum erythropoietin levels returned to normal, compared with wild-type (WT). Hif-2a single allele knockout did not

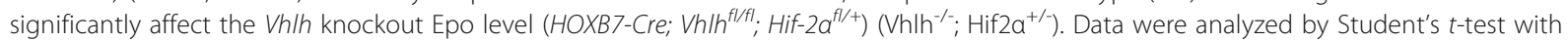
Welch's correction for unequal variance, followed by Bonferoni post-test. $\mathbf{c}$ Erythroid progenitors (TER119+CD71+) were isolated from hemangiomas of two (labeled 1, 2) knockout mice with FACS (purity $80 \%$ ). Genomic DNA was prepared and used for PCR for the recombined, the deleted Vhlh allele (Vh/h del), and the floxed allele (Vh/h flox). No deleted allele was detected in these erythrocyte progenitors. As controls, PCR without template (no template) and PCR with genomic DNA from liver of knockout mice (containing both deleted and floxed alleles; positive control) was performed. $\mathbf{d}$ Hemangiomas were rescued in HOXB7-Cre; Vhl/ $h^{f / f /}$; Hif-2a $a^{f / f l}$ double knockouts. Hemangiomas were counted in H\&E stained liver sections of 2-3 months old mice of indicated genotypes. While the number of hemangiomas per liver section was significantly increased in Vh/h knockouts compared to the wild-type, the number of hemangiomas was significantly decreased in HOXB7-Cre; Vhlh $h^{f / f}$; Hif-2a $a^{f / f l}$ double knockout mice compared with HOXB7-Cre; Vhlih ${ }^{f / A l}$ single knockouts. Each data point represents one liver sample. Counts were averaged from at least 5 sections per liver. $p$-values were calculated using Student's t-test with Welch's correction. *: statistically significant $(p<0.05)$; ns: not significant

adjacent normal liver tissue [Fig. 4d, compare lanes labeled - (no hemangioma) and + (with hemangioma)], indicating that Vhlh null cells were enriched in the hemangiomas.

The lack of Cre + cells in wild-type liver, and enrichment of Vhlh deletion allele in the hemangiomas of the knockouts raised the possibility that Vhlh deletion occurred in an invading or locally expanded cell population. To determine in which cell type Vhlh was inactivated, we used another Cre-reporter: the HOXB7-GFP-Cre driver that can be combined with the Vhlh flox allele. In the HOXB7GFP-Cre driver, Gfp and Cre are made from a bicistronic message, and GFP is readily detectable in the kidney \{Fig. 5a and [25, 29]\}. Using this reporter, we detected GFP expression in isolated, non-hepatic cells interspersed in the liver parenchyma, and within the hemangiomas (Fig. 5b, c). These cells appeared to be leukocytes. Indeed, by PCR, Vhlh inactivation was detectable in leukocytes (CD45+ fraction) isolated from hemangiomas by FACS (Fig. 5d, e). The unrecombined floxed allele was also 


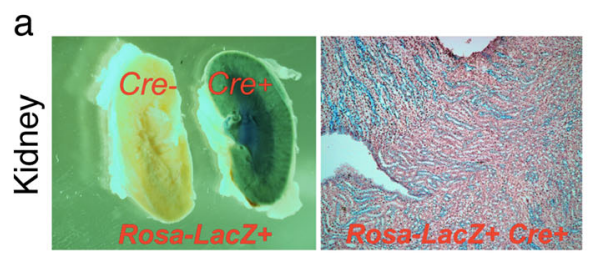

C

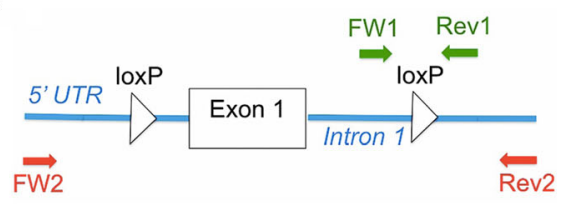

b

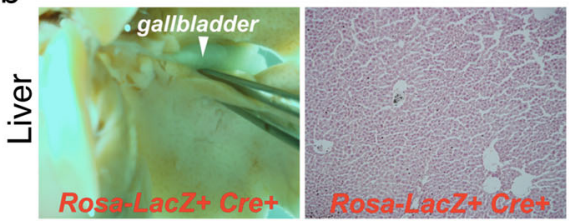

d

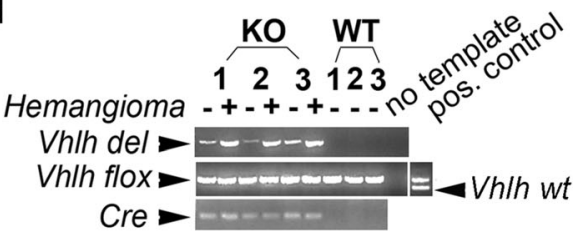

Fig. 4 HOXB7-Cre mediates deletion in liver leukocytes. a, b Rosa-LacZ reporter detects HOXB7-driven Cre expression in the kidney, but not in the liver. a Kidney of Rosa-LacZ+ (Cre-) or HOXB7-Cre; Rosa-LacZ+(Cre+) was stained with $\beta$-galactosidase substrate. b Liver of HOXB7-Cre; Rosa-LacZ+ mouse. Left panels show gross morphological appearance of whole-mount stains (kidneys were sectioned in halves), and right panels show sections prepared from whole-mounts. Strong LacZ signal is seen in medulla and cortex of HOXB7-Cre; Rosa-LacZ+ kidney (a), but not in Cre negative Rosa-LacZ+ kidney (a) or HOXB7Cret; Rosa-LacZ+ liver (b). c Map of the floxed Vhlh allele (based on description by Haase et al. [20]) and locations of primers for detection of wild-type and floxed Vh/h allele (FW1-Rev1, green; primers designed by Rankin et al. [22]) and recombined, deleted allele (FW2-Rev2, red; primers design is as described in Methods). Not drawn to scale. FW, forward primer; Rev, reverse primer; 5'UTR, 5 prime untranslated region; loxP, loxP site. $\mathbf{d}$ By PCR, Vhlh deletion is detected in livers of HOXB7-Cre; Vh/h $h^{f l / f l}$ mice. Genomic DNA was isolated from livers of HOXB7-Cre; Vh/h $h^{f / f l}(\mathrm{KO})$ mice and Cre negative littermates (WT). For each genotype, genomic DNA from three different mice (1-3) was obtained. PCR was performed with primers specific for the wild-type (Vh/h wt), floxed (Vh/h flox) or recombined (deleted) (Vhlh del) alleles using primers described in c. In addition, Cre-specific PCR was performed. Knockout DNA samples were isolated from either liver tissue with healthy appearance (-) or liver tissue with hemangiomas (+). Note that the recombined Vhlh allele (Vhlh del) was only detected in knockout mice, confirming the specificity of PCR. Furthermore, the signal for the recombined allele was much stronger in knockout liver tissue with hemangiomas (+) compared to knockout liver tissue with healthy appearance (-). As controls, PCR was performed without template (no template) or with liver DNA from a Vhlh $h^{f l+}$ mouse (positive control for floxed and wild-type Vhlh alleles)

detectable in this fraction (Fig. 5e), which is not surprising since these leukocytes are heterogeneous, comprising $\mathrm{B}$ cells, T cells, NK cells and myeloid cells (data not shown). Of note, GFP is not detected in the endothelia (Fig. 5b, c), and as shown above (Fig. $2 \mathrm{~d}$ ), the erythrocyte progenitors isolated from the liver of knockout mice did not contain Vhlh deletion allele, either. We therefore conclude that in this mouse model, Vhlh is inactivated in a subset of liver leukocytes.

\section{Vhlh inactivation is detected in granulocytes/neutrophils}

Hoxb7 expression has been observed in granulocytes isolated from murine bone marrow [32]. This would agree with our observation of Vhlh inactivation in leukocytes. We therefore isolated granulocytes (CD11b + SSC-A high) from liver hemangiomas by FACS (Fig. 6a) and were able to detect Vhlh deletion consistently in the granulocyte-enriched fraction (Fig. 6b). Vhlh inactivation was also occasionally observed in the CD11b + SSC-A medium/low fraction, a fraction that contains some granulocytes besides other myeloid cells; and in the nonmyeloid fraction (Fig. 6b). The appearance of Vhlh deletion in these non-granulocyte fractions is inconsistent; it is therefore difficult to assess their functional significance. Consistent with Vhlh inactivation, we also observed significant up-regulation of the Hif- $2 \alpha$ responsive gene Phd3 in granulocytes (Fig. 6c). Taken together, these data indicate that the HOXB7-Cre driver mediates inactivation in a subset of granulocytes.

Among the HIF-dependent pro-angiogenic factors, we have detected increased expression of vascular endothelial growth factor B (VEGFB) and placental growth factor (Plgf) in the liver of knockout mice (data not shown). We used Plgf as a marker to examine the cell type potentially contributing to the liver phenotype. As shown in Fig. 7, both Plgf-positive and negative neutrophils could be observed (Fig. 7a, b). Interestingly, the percentage of Plgf-positive neutrophils was significantly increased ( $>10$ folds) in the liver of knockout mice compared with the wild-type (Fig. 7c).

\section{Hepatic phenotypes were rescued by reconstitution with wild-type hematopoietic stem cells}

To elucidate the contribution of Vhlh null granulocytes to hemangioma formation, we generated bone marrow chimeras. Hematopoietic stem cells were enriched by sorting the Hoechst-negative "side population" (SP) from bone marrow (Fig. 8a) [26]. Lethally irradiated mice were reconstituted with 1000 SP cells, and the chimerism-defined as percentage of peripheral blood leukocytes derived from donor stem cells-was determined one month (knockout recipients) or 2-6 months (wild-type recipients) after transplantation to confirm the success of the transplant (Fig. 8b). A chimerism of $60-80 \%$ was 

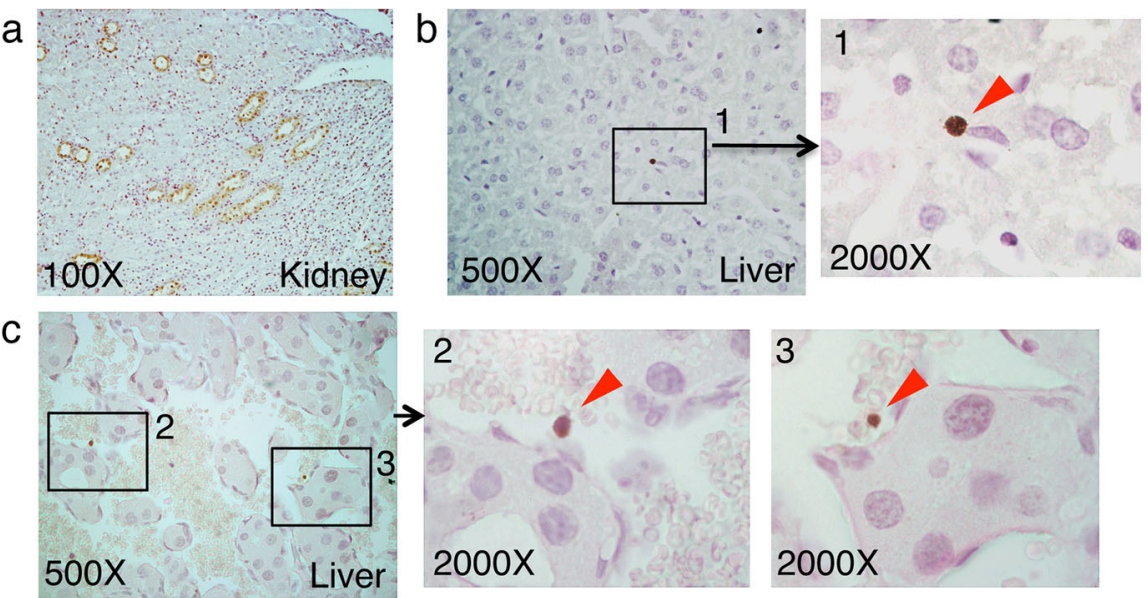

\section{d Negative control} (unstained)
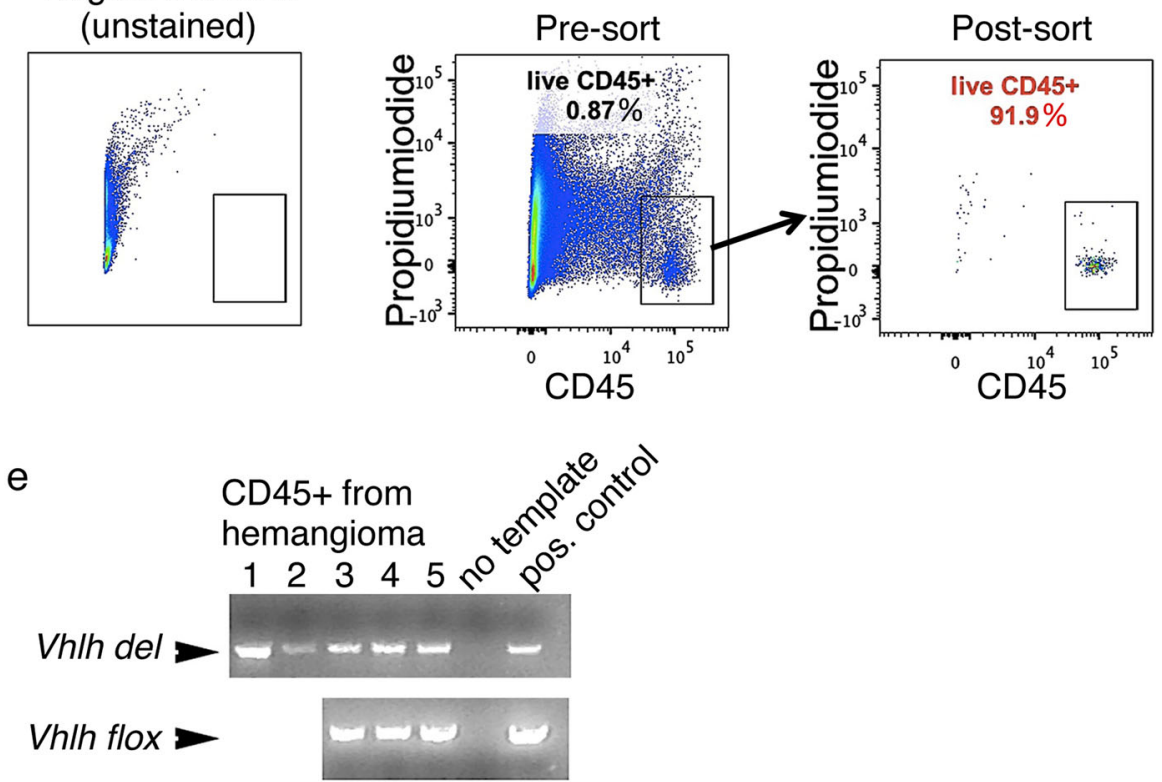

Fig. 5 Deletion of Vhlh in liver leukocytes. a By immunohistochemistry, GFP is prominent in the collecting ducts in kidney of the reporter strain HOXB7-GFP-Cre; Vhlh ${ }^{f l / f l}[25,29]$. b, c GFP is also detectable in single cells interspersed within the liver parenchyma (b1) or within hemangiomas $(\mathbf{c} \mathbf{2}, \mathbf{3})$. d Isolation of leukocytes from livers of HOXB7-Cre; Vh/h/flfl mice. Liver cell suspensions were prepared by mincing livers, digesting with collagenase, and lysing red blood cells with red blood cell lysis buffer. Liver cell suspensions were then stained with the pan-leukocyte marker CD45 and propidium iodide (live/dead stain). Live CD45+ cells were isolated with FACS; debris and doublets were gated out. After the sort, CD45+ fractions were $>90 \%$ pure. e By PCR, Vh/h inactivation was detected in CD45+ leukocyte fraction of 5 independent samples (1-5). Samples 3-5 were additionally examined for the presence of floxed alleles (the amount of DNA samples 1 and 2 were insufficient for additional PCR tests). As control, PCR was performed without template (no template control) or with genomic DNA from a HOXB7-Cre; Vhlh ${ }^{\text {fl/fl }}$ knockout kidney (positive control, which contains both Vh/h-inactivated and wild-type cells)

obtained (Fig. 8c). Control experiments showed that wild-type donor to wild-type recipient transplantation did not cause any liver phenotype (Fig. 8c, d); and that knockout donor to knockout recipient transplantation generated liver hemangioma phenotype with severity indistinguishable from the HOXB7-Cre; $V h l h^{f l / f l}$ mice (Fig. 8c, e). In the wild-type to knockout chimeric mice, hemangiomas were rescued (Fig. 8c, f) or improved (Fig. 8c, g) in $50 \%$ of knockout mice (Fig. 8c, h). The partial rescue could be because the replacement of the host hematopoietic stem cells (chimerism) was not complete. However, it is also possible that other nonbone marrow-derived components might be involved. Interestingly, knockout to wild-type transplantation did not generate the hemangioma phenotype, despite high chimerism (Fig. 8c, i). This indicates that Vhlh inactivation in the hematopoietic component is necessary but insufficient for the hemangioma formation. 

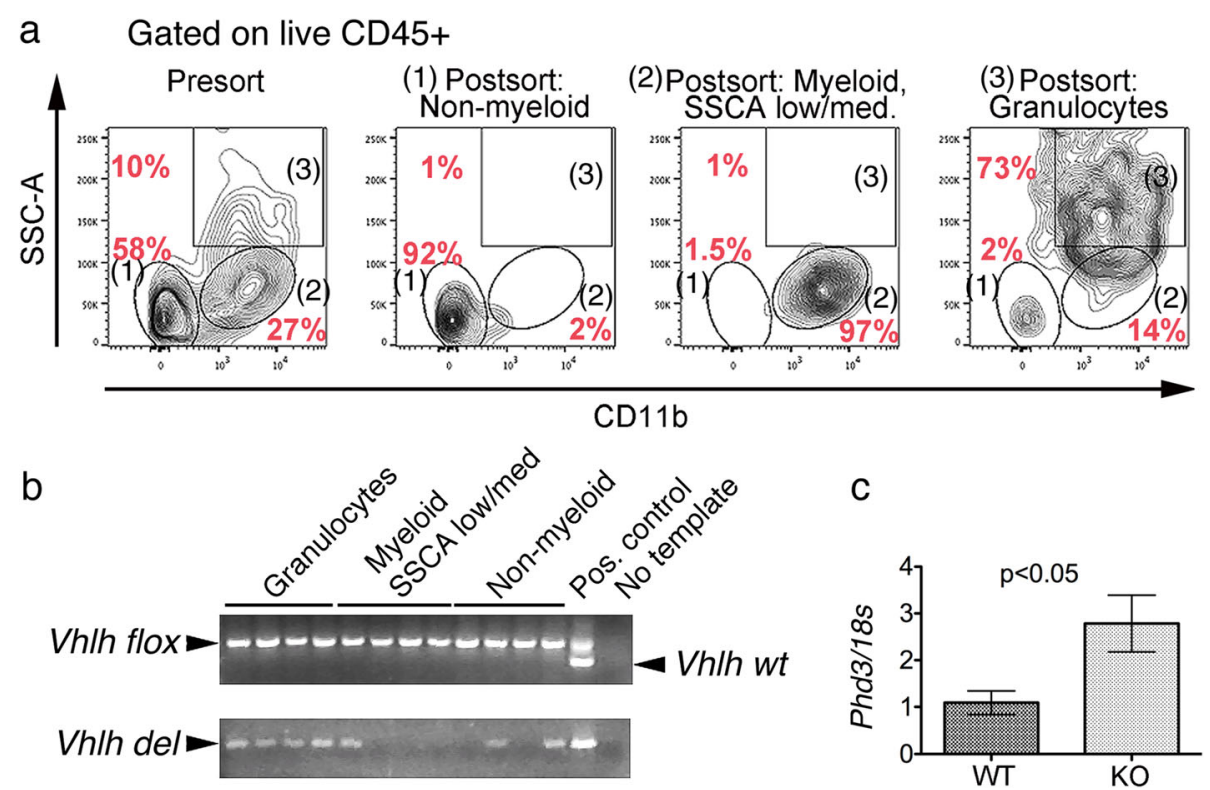

Fig. 6 Vhlh is deleted in granulocytes of HOXB7-Cre; Vh/h/fll mice. a Isolation of (1) non-myeloid cells (CD11b-), (2) other myeloid cells (CD11b + SSCA low/medium), and (3) granulocytes (CD1 1b + SSCA high) from HOXB7-Cre; Vh/ht/fll mice by FACS. Shown are representative FACS-plots before and after sorting. The three populations are indicated in each panel. $\mathbf{b}$ PCR analysis of Vh/h alleles in genomic DNAs isolated from the above cell populations. Recombined Vhlh allele (Vh/h de) is consistently observed in (3) granulocyte-enriched fraction ( 95 \% CD11b+, $70 \%$ CD11b + SSCA high). As control, PCR was performed without template (no template control) or with genomic DNA from the liver of a HOXB7-Cre; Vh/h ${ }^{f / /+}$ mouse (positive control containing Vh/h-floxed and wild-type cells) or a HOXB7-Cre; Vh/h/flf kidney (positive control containing Vh/h-del cells). c Consistent with Vhlh inactivation, the mRNA of Proline-hydroxylase 3 (Phd3), a Hif-2a-responsive gene, is up-regulated in the granulocyte fraction, as assayed by qPCR

\section{Discussion}

The kidney phenotype in HOXB7-Cre; Vhlh ${ }^{f l f l}$ knockout mice develops at $\sim 2$ months of age $\{[25]$ and data not shown\}. In contrast, nascent hemangiomas are already apparent in $75 \%$ of 4-week old mice, and welldeveloped hemangiomas are present in $90 \%$ of 6-week old mice (Fig. 1d). Furthermore, Hif-2 $\alpha$ inactivation ameliorates the hemangioma phenotype, but has no effect on the kidney phenotype. Thus, the liver phenotype is most likely not the result of Vhlh inactivation in the kidney lesion. We cannot exclude the possibility that Hif- $2 \alpha$-induced factors emanating from the kidney are required for liver hemangioma formation. However, this explanation is not favored because other kidney-specific Vhlh knockouts do not develop liver phenotype [11, 33].

Liver hemangiomas have been described previously in germline $\mathrm{Vhlh}^{+/}$mice and in mice with Vhlh inactivation in hepatocytes (PEPCK-Cre or Albumin-Cre driven Vhlh knockout mice) [20, 22, 23]. PEPCK-driven Cre is worth noting because it has dual specificity in kidney (proximal
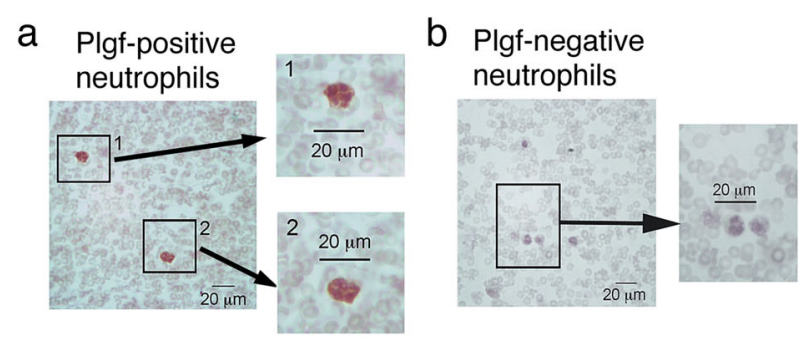

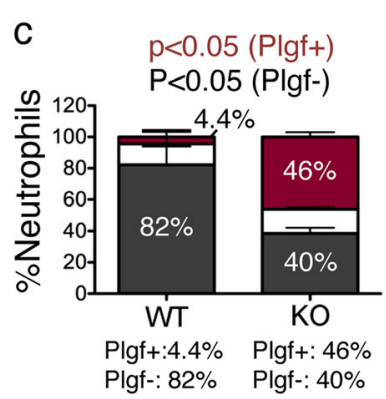

Fig. 7 Plgf is expressed in neutrophils of HOXB7-Cre; Vh/h ${ }^{f / f l}$ knockout mice. $\mathbf{a}$, b Plgf immunohistochemistry of liver sections (brown stain). Nuclei were stained with hematoxylin (light blue). Representatives Plgf $+(\mathbf{a})$ and Plgf- (b) neutrophils localized within hemangiomas of a HOXB7-Cre; $V h / h^{f l / f l}$ knockout mouse are shown. Note the polymorpho-nuclear shape characteristic of neutrophils. c Quantification of Plgf-expressing liver neutrophils (immunohistochemistry); $n=3$ mice per group, total number of neutrophils counted: 38 (WT) and 510 (KO). Neutrophils were classified as strongly Plgf positive (Plgft, dark pink), weakly Plgf positive (Plgf+/-, white) or Plgf negative (Plgf-, grey). A 10-fold increase in the percentage of Plgf + neutrophils was observed in HOXB7-Cre; Vh/h ${ }^{f / f t}$ mice compared to Cre-negative littermates (46 \% versus $4.4 \%$ ) 
a

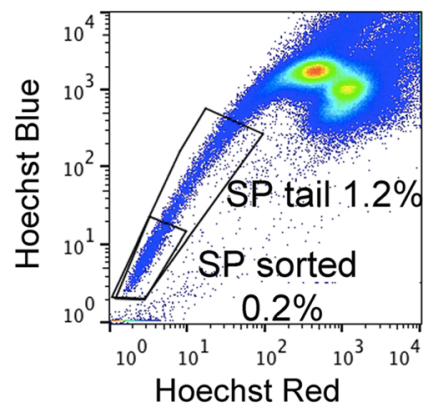

b
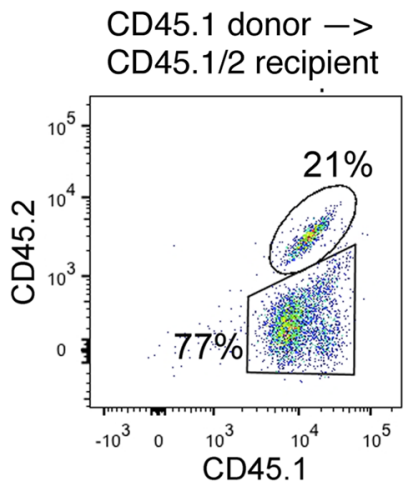

C

\begin{tabular}{|c|c|c|c|c|}
\hline & $\begin{array}{c}\mathrm{WT} \rightarrow \mathrm{WT} \\
\mathrm{n}=7\end{array}$ & $\begin{array}{c}\mathrm{KO} \rightarrow \mathrm{KO} \\
\mathrm{n}=4\end{array}$ & $\begin{array}{c}\mathrm{WT} \rightarrow \mathrm{KO} \\
\mathrm{n}=6\end{array}$ & $\begin{array}{c}\mathrm{KO} \rightarrow \mathrm{WT} \\
\mathrm{n}=7\end{array}$ \\
\hline Chimerism & $80 \%$ & $64 \%$ & $68 \%$ & $80 \%$ \\
\hline $\begin{array}{c}\text { Liver } \\
\text { hemangioma }\end{array}$ & No (7/7) & $\begin{array}{c}\mathrm{KO} \text { level } \\
(4 / 4)\end{array}$ & $\begin{array}{c}\text { No (1/6) } \\
\text { Partial rescue (2/6) } \\
\text { KO level (3/6) }\end{array}$ & No (7/7) \\
\hline
\end{tabular}

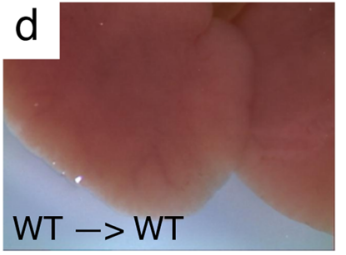

No phenotype $7 / 7$

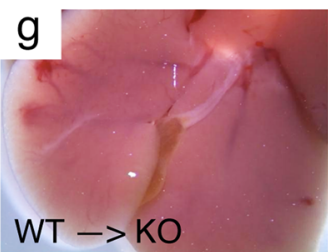

Partial recue $2 / 6$ (delayed or reduced hemangiomas)

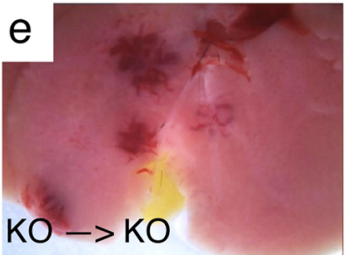

$\mathrm{KO}$ level phenotype $4 / 4$

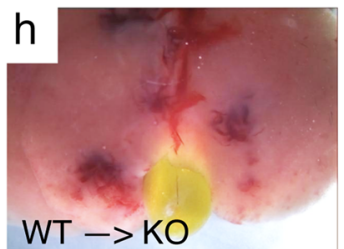

$\mathrm{KO}$ level phenotype $3 / 6$

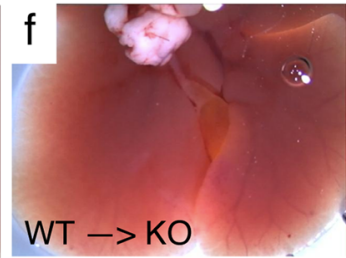

No phenotype $1 / 6$

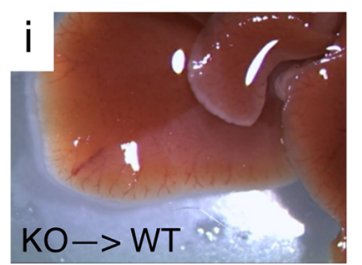

No phenotype $7 / 7$

Fig. 8 Hemangiomas in knockout mice are partially rescued by reconstitution with wild-type hematopoietic stem cells. Hematopoietic stem cells were enriched by sorting Hoechst negative side population (SP) from bone marrow. 8-9-week old wild-type mice or 4-week old HOXB7-Cre; $V h / h^{f / / f l}$ mice were lethally irradiated and transplanted with 1000 SP obtained from 2 to 3 month old HOXB7-Cre; Vh/h ${ }^{f / f l}$ mice (KO), or Cre-negative $V h / h^{f / f f l}$ littermates (WT). a Representative Hoechst stain followed by sorting. Percentage of Hoechst negative cells is indicated. Only the tip of the Hoechst negative tail that contains cells with the least Hoechst fluorescence was collected. b Representative flow data of peripheral blood leukocytes stained with CD45.1 and CD45.2 two months after the transplant (wild-type recipients) or one month after the transplant (HOXB7-Cre; Vh/h ${ }^{f / f l}$ recipients). Recipients were CD45.1/2 double positive and were transplanted with CD45.1 single positive SP. c Summary of transplant experiments. d-i Representative phenotypes of the transplanted chimera. Livers of $\mathrm{KO}$ recipients were obtained one month after the transplant, at $\sim 2$ months of age; livers of WT recipients were obtained at 2, 3 and 6 months after transplantation. Numbers beneath images indicate number of mice with phenotype versus total number of mice analyzed. $\mathbf{d}$ Wild-type SP to wild-type recipients (WT - > WT) did not show any phenotype. e Knockout SP to knockout recipients $\left(\mathrm{KO}->\mathrm{KO}\right.$ ) showed full-penetrant phenotype. $\mathbf{f}-\mathbf{h}$ Hemangiomas are partially rescued in HOXB7-Cre; Vh/h $h^{f l / f l}$ recipient mice (KO) transplanted with SP from Cre negative Vh/h ${ }^{\text {flffl }}$ mice (WT). i Knockout SP to wild-type recipients (KO - > WT) showed no phenotype 
tubules) and liver ( 20-30\% hepatocytes) [22]. Here, we show that HOXB7-Cre driven Vhlh conditional knockout mice also develop hemangiomas in the liver, although unlike previous models, this Cre driver does not mediate recombination in hepatocytes. We were unable to detect Cre activity in hepatocytes using the Rosa-LacZ reporter, and we also did not observe steatosis in hepatocytes, a phenotype characteristic of Vhlh null hepatocytes [20, 22].

The more hepatocyte-specific Cre (Albumin-Cre) driven Vhlh knockout also generated hemangiomas, albeit more at the microscopic level [22]. However, despite superficial similarity of the phenotypes, several findings indicate that the mechanism of hemangioma formation is different in hepatocyte-specific Albumin-Cre driven and HOXB7-Cre driven Vhlh knockout mice. In HOXB7-Cre driven Vhlh knockout mice, hemangiomas develop with higher penetrance ( $90 \%$ vs $40 \%$ ) and at a younger age (4-6 weeks versus 3-8 months) compared to the Albumin-Cre Vhlh knockout mice [20]. Furthermore, the hemangiomas in HOXB7-Cre driven Vhlh knockouts exhibit extramedullary hematopoiesis that is also observed in human hemangioblastoma but not in liver with hepatocyte Vhlh knockout (either Albumin-Cre or PEPCK-Cre driven).

Another difference between the hepatocyte-specific Vhlh knockout mice and the HOXB7-Cre driven Vhlh knockout mice is the pattern of erythropoiesis. Erythropoietin is over-expressed in the knockout mice with hepatocyte-specific Vhlh inactivation [20, 22], as well as in HOXB7-Cre driven Vhlh knockout mice. However, while erythropoietin over-expression induced systemic erythrocytosis-characterized by elevated hematocrit-in PEPCK-Cre and Albumin-Cre driven Vhlh knockout mice [20, 22], erythropoiesis was only increased in HOXB7-Cre driven $V h l h$ knockout mice in specific organs such as liver. There is no increase in hematocrit in HOXB7-Cre driven Vhlh knockouts (data not shown). This pattern of focal erythropoiesis resembles the pattern observed in VHL patients, who develop polycythemia only rarely, despite tumor-associated extramedullary erythropoiesis [34].

By PCR, a stronger signal for the recombined allele was detected in hemangiomas compared to healthy liver tissue, indicating that Vhlh null cells are enriched in hemangiomas. Also, Cre activity was undetectable with the Rosa-LacZ reporter in mice with wild-type Vhlh. Thus, Vhlh inactivation likely occurs in a cell type that is rare in the healthy liver and undergoes expansion or is recruited to the liver when Vhlh is inactivated.

One type of cells that was enriched in hemangiomas is leukocytes. We detected foci of leukocytes (CD45+) adjacent to hemangiomas, and by PCR we detected Vhlh inactivation in leukocytes isolated from hemangiomas (Fig. 5). We further identified granulocytes/neutrophils as the Vhlh mutant cells in this model (Figs. 6 and 7). Furthermore, hemangiomas were partially rescued in
HOXB7-Cre; Vhlh ${ }^{f l / f l}$ mice reconstituted with wildtype hematopoietic stem cells (Fig. 8). Thus, Vhlh inactivation in bone marrow-derived leukocytes contributes to hemangioma formation in this mouse model. Interestingly, Vhlh null leukocytes were not sufficient to induce hemangiomas, since no hemangiomas were observed in the reverse experiment (wild-type mice reconstituted with HOXB7-Cre; Vhlh $^{f l f l}$ hematopoietic stem cells). Thus, inactivation of Vhlh in at least one other cell type besides bone marrow-derived cells is required for hemangioma formation. It may be that HOXB7-Cre driven Vhlh knockout in kidney tubule cells contributes to systemic elevation of Epo, which in turn is required for hemangioma formation in the liver. However, kidney hyperplasia and tubule defects were rescued by inactivation of $H i f-1 \alpha$, but not Hif- $2 \alpha$ [25], whereas other kidney-specific Vhlh knockout mouse models did not develop liver hemangioma $[11,33]$. The other contributing cell types might include embryonic hematopoietic progenitor cells in the liver that fail to migrate to the bone marrow. However, we did not detect Vhlh deletion in the erythrocyte progenitor cells, despite increased number of these progenitors. We did, however, detect Vhlh deletion in liver granulocytes/neutrophils and moderately increased number of Granulocyte/Macrophage/Megakaryocyte/Erythroid (GMME) progenitors cells in the liver (data not shown). This indicates that Vhlh mutant liver-resident granulocyte progenitors may be critical for liver extramedullary erythropoiesis and hemangioma formation. Interestingly, it has been reported that $V H L$ haploid insufficiency in neutrophils contributes to their decreased apoptosis, and thus population expansion, in VHL patients. It may be that liver resident granulocytes/neutrophils undergo expansion and promote angiogenesis. We indeed observed increased population of Plgf-expressing neutrophils in knockout mice compared to wild-type. Therefore both bone marrow-derived and liver-resident granulocytes/ neutrophils are needed for the full penetrance of liver hemangioma phenotype.

We have not observed the hemangioma phenotype in other organs of the Vhlh knockout mice described here. This indicates that a unique hepatic microenvironment may be required. However, since the kidney defects observed in the Hoxb7-Cre; Vhlh $^{f l f l}$ knockout mice include hyper-vascularization and hemorrhage [25], it is tempting to speculate that the activated neutrophils may also contribute to the full extent of the kidney hyperplastic phenotypes. Future studies should address this intriguing possibility.

The finding that Vhlh null granulocytes contribute to hemangioma formation is of significance for understanding hemangioblastoma and other highly vascularized VHL tumors. Since VHL patients are heterozygous for VHL loss-of-function mutations, it is conceivable that inactivation of the remaining wild-type allele could occur in 
more than one cell type (as indeed it does, since patients are prone to develop tumors in several tissues), including those constituting the stromal compartments. Mutations in the cancer stromal cells have been documented that contribute to cancer progression \{reviewed in [12]\}. In particular, neutrophils have been recognized as a major inducer of tumor angiogenesis [35]. Significantly, recent reports have identified CXCR4 (a known HIF target)-expressing neutrophils as a highly pro-angiogenic subtype of neutrophils [36]. It is therefore possible that in VHL patients, $V H L$ inactivation occurs in components of the tumor microenvironment in addition to the tumor itself. Pro-angiogenic $V H L$ null granulocytes/neutrophils could therefore contribute to the development of the tumor vasculature.

\section{Conclusions}

Hemangioblastoma is a serious tumor associated with the VHL disease and is difficult to study because of a lack of animal models. One interesting pathological feature of this disorder is that the endothelial cells are themselves genomically normal. Instead, vascular overgrowth is induced by adjacent non-endothelial cells that exhibit loss of heterozygosity and may be of hematopoietic or embryonic origin. Our mouse model shows that Vhlh inactivation in the "stromal" (non-tumor) cell population, at least in part consisting of granulocytes/neutrophils, can induce abnormal angiogenesis. Furthermore, we show that hemangiomaassociated extramedullary erythropoiesis can occur without Vhlh inactivation taking place in erythrocytes. This system thus represents a good model for studying aspects of the hemangioblastoma found in the human VHL disease.

\begin{abstract}
Abbreviations
ARNT: Aryl hydrocarbon receptor nuclear translocator; ccRCC: Clear-cell renal cell carcinoma; Epo: Erythropoietin; FACS: Fluorescence-activated cell sorting; HIF: Hypoxia-inducible factor; PCR: Polymerase chain reaction; Plgf: Placental growth factor; VEGF: Vascular endothelial growth factor; VHL: von Hippel-Lindau
\end{abstract}

\section{Acknowledgments}

We thank Tracy L. Pritchett and Richard Near for assistance with mouse breeding (TLP, RN) and collection of mouse tissues (TLP). We are grateful to Joel Henderson, Associate Professor of Pathology, who helped interpret the pathology of liver hemangioma and fibrotic lesions. We thank Samir Kamat for testing of primers used for quantitative PCR. Furthermore, we thank the excellent core facilities of the Boston University School of Medicine for assistance: Immunohistochemistry Core (paraffin embedding), Analytical Instrumentation Core (autoblood analyzer) and Flow Cytometry Core (cell sorting and assistance with setting up and analyzing multicolor flow cytometry). We also would like to thank members of the Center for Regenerative Medicine (CReM) at Boston University School of Medicine for help with setting up bone marrow transplants assays: George Murphy, Gustavo Mostoslavsky, and Dolly Thomas.

\section{Funding}

This work was supported by a grant to TH from the National Institutes of Health, USA (\#R01CA109860), a postdoctoral fellowship to HLB from the National Institutes of Health, USA (\#T32HL007501), a core subsidy to HLB/TH from the Clinical and Translational Science Institute (CTSI) at Boston University (UL1-TR000157), and a grant to TH from Ministry of Science and Technology, Taiwan (MOST103-2320-B-008-002-MY3) and a grant to TH from National Health Research Institute, Taiwan (EX105-0501BI).
Availability of data and materials

All data described in this manuscript are freely disseminated. No reagents are generated de novo in this study, but are commercially available.

\section{Authors' contributions}

HLB performed all the experiments described in this manuscript and co-wrote the manuscript. TH contributed to the overall direction of the study and co-wrote the manuscript. Both authors read and approved the final manuscript.

\section{Competing interests}

The authors declare that they have no competing interests.

\section{Consent for publication}

Not applicable.

\section{Ethics approval}

All of the animal procedures were conducted in accordance with the US Public Health Service Policy on Humane Care and Use of Laboratory Animals. Mice used in these studies were maintained in Boston University Medical Center facility according to protocols approved by the Institutional Animal Care and Use Committee. No human tissues or samples were used.

\section{Author details}

${ }^{1}$ Department of Medicine, Boston University School of Medicine, Boston, MA, USA. ${ }^{2}$ Department of Biomedical Sciences and Engineering, National Central University, Chung-li, Taiwan.

Received: 1 July 2016 Accepted: 22 September 2016

Published online: 12 October 2016

\section{References}

1. Gossage L, Eisen T, Maher ER. VHL, the story of a tumour suppressor gene. Nat Rev Cancer. 2014;15(1):55-64

2. Ang SO, Chen H, Gordeuk VR, Sergueeva Al, Polyakova LA, Miasnikova GY, Kralovics R, Stockton DW, Prchal JT. Endemic polycythemia in Russia: mutation in the VHL gene. Blood Cells Mol Dis. 2002;28(1):57-62.

3. Pastore YD, Jelinek J, Ang S, Guan Y, Liu E, Jedlickova K, Krishnamurti L, Prchal JT. Mutations in the VHL gene in sporadic apparently congenital polycythemia. Blood. 2003;101(4):1591-5.

4. Tomasic NL, Piterkova L, Huff C, Bilic E, Yoon D, Miasnikova GY, Sergueeva Al, Niu X, Nekhai S, Gordeuk V, et al. The phenotype of polycythemia due to Croatian homozygous VHL (571C > G:H191D) mutation is different from that of Chuvash polycythemia (VHL 598C > T:R200W). Haematologica. 2013;98(4):560-7.

5. Shen C, Kaelin Jr WG. The VHL/HIF axis in clear cell renal carcinoma. Semin Cancer Biol. 2013;23(1):18-25.

6. Hsu T. Complex cellular functions of the von Hippel-Lindau tumor suppressor gene: insights from model organisms. Oncogene. 2012;31(18):2247-57.

7. Jonasch E, Futreal PA, Davis IJ, Bailey ST, Kim WY, Brugarolas J, Giaccia AJ, Kurban G, Pause A, Frydman J, et al. State of the science: an update on renal cell carcinoma. Mol Cancer Res. 2012;10(7):859-80.

8. Cancer Genome Atlas Research N. Comprehensive molecular characterization of clear cell renal cell carcinoma. Nature. 2013;499(7456):43-9.

9. Sato $Y$, Yoshizato $T$, Shiraishi $Y$, Maekawa S, Okuno $Y$, Kamura T, Shimamura T, Sato-Otsubo A, Nagae G, Suzuki H, et al. Integrated molecular analysis of clear-cell renal cell carcinoma. Nat Genet. 2013;45(8):860-7.

10. Brugarolas J. Molecular genetics of clear-cell renal cell carcinoma. J Clin Oncol. 2014;32(18):1968-76.

11. Wang SS, Gu YF, Wolff N, Stefanius K, Christie A, Dey A, Hammer RE, Xie XJ, Rakheja D, Pedrosa I, et al. Bap1 is essential for kidney function and cooperates with Vhl in renal tumorigenesis. Proc Natl Acad Sci U S A. 2014;111(46):16538-43.

12. Eng C, Leone G, Orloff MS, Ostrowski MC. Genomic alterations in tumor stroma. Cancer Res. 2009:69(17):6759-64.

13. Maher ER, Neumann HP, Richard S. von Hippel-Lindau disease: a clinical and scientific review. Eur J Hum Genet. 2011;19(6):617-23.

14. Lee JY, Dong SM, Park WS, Yoo NJ, Kim CS, Jang JJ, Chi JG, Zbar B, Lubensky IA, Linehan WM, et al. Loss of heterozygosity and somatic mutations of the VHL tumor suppressor gene in sporadic cerebellar hemangioblastomas. Cancer Res. 1998;58(3):504-8.

15. Vortmeyer AO, Gnarra JR, Emmert-Buck MR, Katz D, Linehan WM, Oldfield $\mathrm{EH}$, Zhuang Z. von Hippel-Lindau gene deletion detected in the stromal cell 
component of a cerebellar hemangioblastoma associated with von HippelLindau disease. Hum Pathol. 1997;28(5):540-3.

16. Vortmeyer AO, Huang SC, Pack SD, Koch CA, Lubensky IA, Oldfield EH, Zhuang Z. Somatic point mutation of the wild-type allele detected in tumors of patients with VHL germline deletion. Oncogene. 2002;21(8):1167-70.

17. Park DM, Zhuang Z, Chen L, Szerlip N, Maric I, Li J, Sohn T, Kim SH, Lubensky IA Vortmeyer AO, et al. von Hippel-Lindau disease-associated hemangioblastomas are derived from embryologic multipotent cells. PLoS Med. 2007;4(2):e60.

18. Vortmeyer AO, Frank S, Jeong SY, Yuan K, Ikejiri B, Lee YS, Bhowmick D, Lonser RR, Smith R, Rodgers G, et al. Developmental arrest of angioblastic lineage initiates tumorigenesis in von Hippel-Lindau disease. Cancer Res. 2003;63(21):7051-5.

19. Vortmeyer AO, Tran MG, Zeng W, Glasker S, Riley C, Tsokos M, Ikejiri B, Merrill MJ, Raffeld M, Zhuang Z, et al. Evolution of VHL tumourigenesis in nerve root tissue. J Pathol. 2006;210(3):374-82.

20. Haase VH, Glickman JN, Socolovsky M, Jaenisch R. Vascular tumors in livers with targeted inactivation of the von Hippel-Lindau tumor suppressor. Proc Natl Acad Sci U S A. 2001;98(4):1583-8.

21. Ma W, Tessarollo L, Hong SB, Baba M, Southon E, Back TC, Spence S, Lobe CG, Sharma N, Maher GW, et al. Hepatic vascular tumors, angiectasis in multiple organs, and impaired spermatogenesis in mice with conditional inactivation of the VHL gene. Cancer Res. 2003;63(17):5320-8.

22. Rankin EB, Higgins DF, Walisser JA, Johnson RS, Bradfield CA, Haase VH. Inactivation of the arylhydrocarbon receptor nuclear translocator (Arnt) suppresses von Hippel-Lindau disease-associated vascular tumors in mice. Mol Cell Biol. 2005;25(8):3163-72.

23. Kleymenova E, Everitt II, Pluta L, Portis M, Gnarra JR, Walker CL. Susceptibility to vascular neoplasms but no increased susceptibility to renal carcinogenesis in Vhl knockout mice. Carcinogenesis. 2004;25(3):309-15.

24. Rankin EB, Rha J, Unger TL, Wu CH, Shutt HP, Johnson RS, Simon MC, Keith $\mathrm{B}$, Haase VH. Hypoxia-inducible factor-2 regulates vascular tumorigenesis in mice. Oncogene. 2008;27(40):5354-8.

25. Pritchett TL, Bader HL, Henderson J, Hsu T. Conditional inactivation of the mouse von Hippel-Lindau tumor suppressor gene results in wide-spread hyperplastic, inflammatory and fibrotic lesions in the kidney. Oncogene. 2015;34(20):2631-9.

26. Goodell MA, Brose K, Paradis G, Conner AS, Mulligan RC. Isolation and functional properties of murine hematopoietic stem cells that are replicating in vivo. J Exp Med. 1996;183(4):1797-806.

27. Mostoslavsky G, Kotton DN, Fabian AJ, Gray JT, Lee JS, Mulligan RC. Efficiency of transduction of highly purified murine hematopoietic stem cells by lentiviral and oncoretroviral vectors under conditions of minimal in vitro manipulation. Mol Ther. 2005;11(6):932-40.

28. Yu J, Carroll TJ, McMahon AP. Sonic hedgehog regulates proliferation and differentiation of mesenchymal cells in the mouse metanephric kidney. Development. 2002;129(22):5301-12.

29. Zhao H, Kegg H, Grady S, Truong HT, Robinson ML, Baum M, Bates CM. Role of fibroblast growth factor receptors 1 and 2 in the ureteric bud. Dev Biol. 2004;276(2):403-15.

30. Li J, Hale J, Bhagia P, Xue F, Chen L, Jaffray J, Yan H, Lane J, Gallagher PG, Mohandas $\mathrm{N}$, et al. Isolation and transcriptome analyses of human erythroid progenitors: BFU-E and CFU-E. Blood. 2014;124(24):3636-45.

31. Soriano P. Generalized lacZ expression with the ROSA26 Cre reporter strain. Nat Genet. 1999;21(1):70-1.

32. Sasmono RT, Ehrnsperger A, Cronau SL, Ravasi T, Kandane R, Hickey MJ, Cook AD, Himes SR, Hamilton JA, Hume DA. Mouse neutrophilic granulocytes express mRNA encoding the macrophage colony-stimulating factor receptor (CSF-1R) as well as many other macrophage-specific transcripts and can transdifferentiate into macrophages in vitro in response to CSF-1. J Leukoc Biol. 2007;82(1):111-23.

33. Frew IJ, Thoma CR, Georgiev S, Minola A, Hitz M, Montani M, Moch H, Krek W. PVHL and PTEN tumour suppressor proteins cooperatively suppress kidney cyst formation. Embo J. 2008;27(12):1747-57.

34. Glasker S, Kruger MT, Klingler JH, Wlodarski M, Klompen J, Schatlo B, Hippchen B, Neumann HP, Van Velthoven V. Hemangioblastomas and neurogenic polyglobulia. Neurosurgery. 2013;72(6):930-5.

35. Tazzyman S, Lewis CE, Murdoch C. Neutrophils: key mediators of tumour angiogenesis. Int J Exp Pathol. 2009;90(3):222-31.

36. Christoffersson G, Vagesjo E, Vandooren J, Liden M, Massena S, Reinert RB, Brissova M, Powers AC, Opdenakker G, Phillipson M. VEGF-A recruits a proangiogenic MMP-9-delivering neutrophil subset that induces angiogenesis in transplanted hypoxic tissue. Blood. 2012;120(23):4653-62.

\section{Submit your next manuscript to BioMed Central and we will help you at every step:}

- We accept pre-submission inquiries

- Our selector tool helps you to find the most relevant journal

- We provide round the clock customer support

- Convenient online submission

- Thorough peer review

- Inclusion in PubMed and all major indexing services

- Maximum visibility for your research

Submit your manuscript at www.biomedcentral.com/submit
Biomed Central 